\title{
Relative Competitiveness and Virulence of Four Clonal Lineages of Cephalosporium maydis from Egypt Toward Greenhouse-Grown Maize
}

\author{
Kurt A. Zeller, Department of Plant Pathology, Throckmorton Plant Sciences Center, Kansas State University, \\ Manhattan 66506-5502; Abou-Serie M. Ismael, Elhamy M. El-Assiuty, Zeinab M. Fahmy, and Fawzia M. Bek- \\ heet, Maize, Sorghum and Sugar Diseases Section, Plant Pathology Research Institute, Agricultural Research Cen- \\ ter, 9 Gamaa Street, Giza, Egypt; and John F. Leslie, Department of Plant Pathology, Kansas State University, \\ Manhattan 66506-5502
}

\begin{abstract}
Zeller, K. A., Ismael, A.-S. M., El-Assiuty, E. M., Fahmy, Z. M., Bekheet, F. M., and Leslie, J. F. 2002. Relative competitiveness and virulence of four clonal lineages of Cephalosporium maydis from Egypt toward greenhouse-grown maize. Plant Dis. 86:373-378.

Four clonal lineages of Cephalosporium maydis, a soilborne vascular wilt pathogen that causes late wilt of maize, were differentiated previously with molecular markers. In Egypt, this fungus can cause significant losses in infected susceptible plants. In greenhouse tests of individual isolates we found that these lineages differ in their virulence toward a series of maize accessions commonly used in Egyptian maize breeding programs. We also determined the relative competitiveness of representatives of the four lineages when incorporated into the soil as a mixed inoculum. The lineage (IV) with greatest mean disease incidence (virulence), when tested alone, was the least competitive on susceptible maize accessions when coinoculated as a component of mixed inocula of all four lineages. In these coinoculation experiments, one of the less-virulent lineages (II) dominated (70\% of infections) and appeared to be the most competitive. These results suggest that virulence and competitive ability are not the same in this hostpathogen system. These results also suggest that standard protocols that rely on mixed inocula for resistance screening need to be altered, and that the relative proportion of the different lineages of the pathogen recovered in a field may be influenced by the maize variety/hybrid planted.
\end{abstract}

Additional keywords: AFLP, late wilt, stalk rot, Zea mays

Late wilt of maize, caused by Cephalosporium maydis Samra, Sabet \& Hingorani, is the most economically important fungal disease of maize (Zea mays L.) in Egypt $(6,9,18,21)$. Disease symptoms first become apparent during tasseling as a rapid wilting of the lower leaves, and progress to produce characteristic hollow and shrunken stalks with a dark yellow-tobrown or black stained pith (6). C. maydis is a soilborne vascular wilt pathogen that penetrates the root tissues and colonizes the xylem (16). More rarely, this pathogen has been reported as seedborne (5), and with high inoculum levels can cause seed rot or preemergence damping-off of maize (19). In infested fields, up to $80 \%$ of susceptible plants may be infected, and yield losses may approach $40 \%$ (20). No sexual stage is known for $C$. maydis, and until recently (26) there has been very little information on genetic variation and population structure for this fungal pathogen.

Corresponding author: John F. Leslie

E-mail: jfl@plantpath.ksu.edu

Accepted for publication 26 November 2001.

Publication no. D-2002-0128-01R

(C) 2002 The American Phytopathological Society
We used amplified fragment length polymorphisms (AFLPs) (25) to describe the genetic diversity of $C$. maydis in Egypt (26). We identified a set of four AFLP primer pairs that could clearly delineate four lineage groups within a broad geographic sample of $C$. maydis field collections. More detailed characterizations of these populations (17) are in progress, but at present there is almost no information as to competitiveness or virulence differences within and among these lineage groups. Previously, Zeller et al. (26) determined that maize germplasm in Egyptian resistance breeding programs had been challenged primarily with isolates belonging to two of the known four genetic lineages. Before the information on the genetic differentiation of the four lineages can be used effectively, however, we need to know if there are any differences in virulence or competitiveness correlated to the observed genetic subdivisions.

The primary goal of this study was to compare the competitive ability and relative virulence among representative isolates drawn from these four lineages. Our specific objectives were: (i) to demonstrate Koch's postulates with representative strains from all four lineages, (ii) to assess the virulence, under greenhouse conditions, of representative isolates within these line- ages toward a series of maize accessions commonly used in the Egyptian national maize breeding program or commonly found in farmers' fields, and (iii) to determine the relative competitiveness of representative isolates within these lineages in terms of their ability to colonize maize plants grown under greenhouse conditions. Our working hypothesis was that these isolates did not differ in virulence and/or the ability to colonize maize plants grown under greenhouse conditions. The phytopathological importance of the AFLPidentified lineages is more significant if these molecular differences are correlated with the ability to cause disease. A preliminary report of portions of this work has been published (4).

\section{MATERIALS AND METHODS}

Terminology and experimental design. We tested two concepts in this study. We attributed the differences that we observed here to differences in "virulence", i.e., the ability of the fungus to cause disease on a specific host genotype. Plants are either diseased or not, although they may develop symptoms at different times, and there is no difference in the degree of disease caused by different isolates of the pathogen.

Our first replicated experiment was designed to determine whether there are virulence differences among isolates and lineages of $C$. maydis on a set of maize accessions (Table 1) that have served as parental lines in Egyptian maize breeding programs. We conducted virulence assays by analyzing two replicate experiments that contained identical fungal isolates and maize accessions, and were initiated on 19 February 1998 and 2 March 1999. We tested the full set of 20 isolates (Table 2) on the seven maize accessions. Individual pots for these experiments were set up and inoculated with $C$. maydis as described below. Each treatment consisted of four replicate pots of at least five plants of each maize accession with each $C$. maydis isolate and included a total of four uninoculated control pots arrayed in blocks in the greenhouse. At the end of each experimental replicate, we compiled the data on numbers of symptomatic plants and determined mean infectivity for each isolate $x$ accession combination. We took tissue 
samples from one to five plants per maize accession per fungal lineage in the first experimental replicate, isolated and cultured C. maydis (described below), and ran AFLP analyses to confirm that the strain added to the pot was the same as the one recovered from the host plant.

Our second replicated experiment was designed to examine relative competitive ability of a smaller set of representative isolates drawn from the four lineages on a single, generally susceptible cultivar. We use the term "competitive" here to denote the differences observed in these experiments, which could potentially measure one or more of the ability to grow saprophytically in the soil, the ability to enter the plant, or the ability to colonize the plant and exclude competitors, if there are multiple infections.

In these replicated experiments, we mixed equal volumes of inoculum of six isolates (Table 2) drawn from the four lineages into the soil (as described below). Each of these isolates produced disease symptoms in the preceding virulence experiments (data not shown). We then planted these pots with the susceptible local maize variety Boushey (as described below). Each replicated experiment consisted of 12 replicate pots of Boushey containing at least five plants and four uninoculated control pots of Boushey arrayed in blocks in the greenhouse. We allowed the plants to grow and develop disease symptoms, then isolated $C$. maydis from one to four symptomatic internodes of each symptomatic plant, and used AFLP data to determine which lineages could be recovered from the resulting diseased susceptible host plant. We analyzed two separate experimental replicates initiated on 29 April 1998 and 1 January 1999.

Strains and growth conditions. We assayed 20 strains (Table 2) that were collected from symptomatic field-grown maize in six different Egyptian governates during the 1997 growing season (26). The
AFLP profiles of these isolates were previously examined and each isolate was assigned to one of four lineages (26). Diagnostic AFLP markers were used to distinguish the four lineages.

Each strain was grown on potato dextrose agar (PDA) $+2 \mathrm{~g} /$ liter yeast extract (Difco, Detroit, MI) (PDA+YE) for 6 days after the strain had initially covered the surface of the plate at $28^{\circ} \mathrm{C}$ in the dark. A 10 -mm-diameter agar disk from this culture was used to inoculate a $300-\mathrm{ml}$ bottle containing $70 \mathrm{~g}$ of autoclaved sorghum grain (autoclaved for $30 \mathrm{~min}$ ). Inoculated bottles were incubated at room temperature (26 to $30^{\circ} \mathrm{C}$ ) on the lab bench until the sorghum grain was completely colonized (approximately 3 to 4 weeks) prior to soil inoculation. A different batch of inoculum was prepared for each of the four experimental replicates (two for competition and two for virulence). Strains were preserved for long-term storage at Kansas State University and the Plant Pathology Research Institute as spore/hyphal fragment suspensions in $15 \%$ glycerol frozen at $-70^{\circ} \mathrm{C}$.

Greenhouse virulence assays and fungal recovery. Clay pots (20 cm diameter) were filled with a mixture of approximately $1.7 \mathrm{~kg}$ of sterilized Nile Silt soil, 25 $\mathrm{g}$ and $2 \mathrm{~g}$, respectively, of superphosphate and $\mathrm{K}_{2} \mathrm{SO}_{4}$. Approximately $50 \mathrm{~g}$ (wet weight) of $C$. maydis colonized sorghum seed inoculum per pot was added to the soil, and the seed and soil mixed thoroughly by stirring. In the competition study, inoculum from six strains from the four lineages (Table 2) was added equally, with the combined inoculum totaling approximately $50 \mathrm{~g}$ (wet weight) per pot, and the soil and colonized seed again mixed thoroughly by stirring. Pots were sown with seven seeds of a single maize accession with four replicate pots for each treatment. The number of seeds that germinated ranged from three to seven per pot. Pots were placed in a greenhouse and watered every 3 days. At 15, 30, and 45 days after planting, approximately $1.5 \mathrm{~g}$ $\mathrm{NH}_{4} \mathrm{NO}_{3}$ per pot was added to the soil surface and watered in. Disease symptoms began to appear approximately 60 days after sowing. Pots were examined at weekly intervals thereafter, and symptomatic plants removed when they were identified. Fungal isolates were recovered from internodes of symptomatic plants as described below.

C. maydis was isolated from the internodes of symptomatic plants by splitting a surface-sterilized stalk (wiped with a cloth

Table 2. Strain numbers, amplified fragment length polymorphism lineages (AFLP), and Egyptian political governate of origin for Cephalosporium maydis strains used in virulence and competition studies

\begin{tabular}{lcc}
\hline Strain $^{\mathbf{v}}$ & Lineage $^{\mathrm{w}}$ & Governate $^{\mathrm{x}}$ \\
\hline $10792^{\mathrm{y}}$ & IV & El-Behira \\
$10793^{\mathrm{z}, \mathrm{y}}$ & I & Kafer El-Shiekh \\
$10799^{\mathrm{z}}$ & III & Gharbya \\
$10800^{\mathrm{y}}$ & II & Gharbya \\
$10803^{\mathrm{z}}$ & IV & Gharbya \\
$10805^{\mathrm{z}}$ & III & Minoufya \\
10806 & I & Menia \\
$10812^{\mathrm{z}}$ & II & Minoufya \\
$10816^{\mathrm{y}}$ & IV & Minoufya \\
10819 & IV & Giza \\
10820 & IV & Kafr El-Shiekh \\
$10824^{\mathrm{y}}$ & I & Giza \\
10825 & I & Giza \\
10826 & II & Beni-Suef \\
10830 & III & Beni-Suef \\
10833 & II & Menia \\
$10834^{\mathrm{y}}$ & III & Menia \\
10837 & II & Sharkya \\
10840 & II & Sohag \\
10844 & II & Qena \\
\hline
\end{tabular}

${ }^{v}$ Kansas State University culture collection numbers.

${ }^{w}$ AFLP lineage as described in Zeller et al. (26).

$x$ Egyptian governate from which the strain was recovered from maize with late wilt disease symptoms in September 1997.

${ }^{y}$ Used in soil coinoculation studies (Table 4).

${ }^{z}$ Low virulence isolate not included in statistical comparisons (Tables 1 and 3 ).

Table 1. Mean percent disease incidence of seven maize accessions caused by 15 isolates ${ }^{\mathrm{v}}$ drawn from four lineages of Cephalosporium maydis from single isolate inoculation tests for virulence

\begin{tabular}{|c|c|c|c|c|c|c|c|c|}
\hline \multirow[b]{2}{*}{ C. maydis lineagew } & \multicolumn{8}{|c|}{ Maize accession } \\
\hline & Giza 4 & Giza 102 & Giza 221D & Giza 249C & Giza 251B & Giza 307A & K-64 & Mean \\
\hline $\begin{array}{l}\mathrm{I} \\
(\mathrm{n}=3)\end{array}$ & $\begin{array}{l}53 \mathrm{a}^{\mathrm{x}, \mathrm{y}} \\
(42,22-80)^{\mathrm{z}}\end{array}$ & $\begin{array}{l}95 \mathrm{a} \\
(85,82-100)\end{array}$ & $\begin{array}{l}43 \mathrm{a} \\
(40,30-67)\end{array}$ & $\begin{array}{l}91 \mathrm{ab} \\
(90,71-100)\end{array}$ & $\begin{array}{l}48 \mathrm{ab} \\
(42,30-88)\end{array}$ & $\begin{array}{l}100 \mathrm{a} \\
(81,100-100)\end{array}$ & $\begin{array}{l}94 \mathrm{a} \\
(83,81-100)\end{array}$ & $\begin{array}{l}75 \mathrm{~b} \\
(66,68-85)\end{array}$ \\
\hline $\begin{array}{l}\text { II } \\
(\mathrm{n}=6)\end{array}$ & $\begin{array}{l}29 \mathrm{~b} \\
(26,6-50)\end{array}$ & $\begin{array}{l}82 \mathrm{~b} \\
(76,47-100)\end{array}$ & $\begin{array}{l}49 \mathrm{a} \\
(45,31-78)\end{array}$ & $\begin{array}{l}86 \mathrm{ab} \\
(87,52-100)\end{array}$ & $\begin{array}{l}64 \mathrm{a} \\
(62,34-100)\end{array}$ & $\begin{array}{l}94 \mathrm{a} \\
(90,77-100)\end{array}$ & $\begin{array}{l}80 \mathrm{~b} \\
(70,37-100)\end{array}$ & $\begin{array}{l}69 \mathrm{c} \\
(65,53-81)\end{array}$ \\
\hline $\begin{array}{l}\text { III } \\
(\mathrm{n}=2)\end{array}$ & $\begin{array}{l}26 \mathrm{~b} \\
(14,16-29)\end{array}$ & $\begin{array}{l}98 \mathrm{a} \\
(85,92-100)\end{array}$ & $\begin{array}{l}55 \mathrm{a} \\
(41,40-71)\end{array}$ & $\begin{array}{l}83 \mathrm{~b} \\
(75,70-95)\end{array}$ & $\begin{array}{l}39 \mathrm{~b} \\
(35,17-64)\end{array}$ & $\begin{array}{l}94 \mathrm{a} \\
(73,90-100)\end{array}$ & $\begin{array}{l}78 \mathrm{~b} \\
(65,62-90)\end{array}$ & $\begin{array}{l}67 \mathrm{c} \\
(55,58-78)\end{array}$ \\
\hline $\begin{array}{l}\text { IV } \\
(n=4)\end{array}$ & $\begin{array}{l}59 \mathrm{a} \\
(49,34-90)\end{array}$ & $\begin{array}{l}100 \mathrm{a} \\
(96,88-100)\end{array}$ & $\begin{array}{l}62 \mathrm{a} \\
(62,46-82)\end{array}$ & $\begin{array}{l}96 \mathrm{a} \\
(91,80-100)\end{array}$ & $\begin{array}{l}65 \mathrm{a} \\
(54,25-100)\end{array}$ & $\begin{array}{l}96 \mathrm{a} \\
(84,81-100)\end{array}$ & $\begin{array}{l}95 \mathrm{a} \\
(83,83-100)\end{array}$ & $\begin{array}{l}82 \mathrm{a} \\
(74,74-87)\end{array}$ \\
\hline Mean & 42 & 94 & 52 & 89 & 54 & 96 & 87 & 73 \\
\hline
\end{tabular}

${ }^{v}$ See Table 2 for isolates included in analysis.

${ }^{w}$ Lineages as defined by amplified fragment length polymorphism (AFLP) similarity in Zeller et al. (26).

${ }^{x}$ Data values represent the percentage of infected plants from four pots per replication with at least five plants per pot and two experimental replications.

${ }^{y}$ Mean percent infection between lineages on individual maize accessions is not significantly different $(P>0.05)$ if followed by the same letter. Significance was estimated by pairwise comparisons of least-square means for each class.

${ }^{\mathrm{z}}$ Overall means for each maize accession and absolute mean infection ranges in observed percent infection for each lineage $\times$ accession pairing when all 20 isolates (Table 2) are retained is indicated in parentheses (mean of all 20 isolates, lower limit - upper limit for 15 included isolates). 
soaked in $5 \% \mathrm{Na}$ hypochlorite, then dipped in $70 \%$ ethanol and flamed) with a sterile knife and transferring a small portion of the discolored vascular bundle to PDA+YE. Plates were incubated at $28^{\circ} \mathrm{C}$ for 2 to 4 days in the dark. Putative $C$. maydis colonies were then subcultured to fresh PDA+YE and incubated an additional 3 to 5 days. These plates were flooded with $5 \mathrm{ml}$ of sterile $\mathrm{H}_{2} \mathrm{O}$ and swirled gently. A loopful of the resulting suspension was then streaked on PDA+YE and incubated for 3 to 4 days. Well-separated colonies were subcultured to fresh PDA+YE and incubated for 3 to 5 days. These plates were flooded with $3 \mathrm{ml}$ of $3: 17$ glycerol:water and swirled gently. The resulting suspension from these single-spored colonies was removed from the plate and then frozen at $-70^{\circ} \mathrm{C}$. All single-spored isolates were confirmed as $C$. maydis based on morphological characters.

DNA isolation. We grew cultures of $C$. maydis and extracted DNA with a modification of the cetyltrimethylammoniumbromide (CTAB) method of Murray and Thompson (12) as previously described (10). We estimated final DNA concentrations densitometrically against HindIIIdigested bacteriophage $\lambda$ DNA on agarose gels with an Applied Biosystems IS-1000 digital imaging system (Alpha Inotech Corp., San Leandro, CA).

AFLPs. We generated AFLP profiles (25) as described previously (26) for all of the isolates recovered from both repetitions of the competition experiment, and from representative strains from both repetitions of the other experiments. Core sequences for the specific primers that we used are: $E c o+\mathrm{NN}=5^{\prime}$-AGACTGCGTACCAATTC$3^{\prime}, \quad M s e+\mathrm{NN}=5^{\prime}$-GATGAGTCCTGAG TAA-3'. We utilized the following specific primer combinations Eco+AA/ Mse+CA, $E c o+\mathrm{AA} / \mathrm{Mse}+\mathrm{CC}, \quad E c o+\mathrm{AA} / \mathrm{Mse}+\mathrm{CG}$, and $E c o+\mathrm{AA} / \mathrm{Mse}+\mathrm{GA}$ to identify the lineage of the recovered strains. The EcoRI primers in the final reaction mixes were end-labeled with ${ }^{33} \mathrm{P}$, and fragments were separated in $6 \%$ polyacrylamide gels (Long Ranger, FMC, Rockland, MD). Gels were dried, and then exposed to autoradiography film (Classic Blue Sensitive, Molecular Technologies, St. Louis, MO) for 3 to 7 days at room temperature to visualize banding patterns. The resulting AFLP profiles were compared to those of standard strains to identify the lineage of the strains recovered.

Statistical analyses. For the comparative analyses of virulence of individual isolates on multiple maize accessions experiment, arcsine transformed mean percent infection values were analyzed with SAS v6.11 (SAS Institute, Cary, NC). A General Linear Model (GLM) procedure was used to compare differences between experimental repetitions, among maize accessions, among C. maydis lineages, for isolates nested within their respective line- ages, and for two- and three-way interactions among these factors.

For the competition experiment, we used AFLP fingerprints to identify the isolate to lineage and determined the number, and lineage distribution, of the recovered isolates from each plant. Before comparing the results, the data set was simplified to simple presence or absence of a lineage from a given symptomatic plant. We then converted these raw data to percent recovery for each lineage from each experimental replicate and compared the two sets of categorical data with $\chi^{2}$ tests to determine whether there were differences in recovery frequency for lineages in each replicate, and whether the different lineages were recovered with relative equal frequencies.

\section{RESULTS}

Koch's postulates. We demonstrated Koch's postulates for all isolates from all four $C$. maydis lineages, in that all isolates were initially recovered from infected maize plants in the field (26). All isolates used in the virulence experiment could infect all of the maize accessions at least some of the time (Table 1), showing that they all were capable of causing disease and were potentially pathogenic in this greenhouse assay system. Noninoculated control plants did not develop late wilt symptoms.

Tests of virulence toward different host accessions. We define a "resistant" maize accession in this study, perhaps arbitrarily, as having an average disease incidence less than $50 \%$, a "moderately resistant" maize accession as having an average disease incidence between 50 and $70 \%$, and a "susceptible" maize accession as having an average disease incidence greater than $70 \%$. Based on the percent diseased plants, Giza 4 is, at least relatively, resistant to $C$. maydis, Giza 221D and Giza 251B are moderately resistant, and Giza 307A, K-64, Giza 102, and Giza 249C are susceptible (Tables 1 and 3). We excluded isolates 10793 (lineage I), 10812 (lineage II), 10799 and 10805 (lineage III), and 10803 (lineage IV) from the GLM analysis because their mean disease incidence rate across the seven maize acces- sions was always less than 50\%. Among the four susceptible maize accessions, all of the plants within a fungal isolate $x$ maize accession set often were symptomatic. Although a few interactions resulted in repeatedly low disease incidence, e.g., $10793 \times$ Giza 307A (8\%), and 10803 and $10812 \times$ K-64 (10 and 7\%, respectively), it was unusual for any of the susceptible accessions to have fewer than $50 \%$ diseased plants with any of the fungal isolates. Among the moderately resistant accessions, the percent diseased plants was usually between 25 and $75 \%$. Exceptions include 10805 and $10812 \times$ Giza 221D and 10799, and $10803 \times$ Giza 251B, which were below $25 \%$ disease incidence, and 10819, 10820, 10826, and $10833 \times$ Giza $251 \mathrm{~B}$, in which more than $75 \%$ disease incidence occurred. For the most resistant accession (Giza 4), disease incidence exceeded $50 \%$ only in interactions with strains 10792, 10806, 10816, 10819, and 10824.

In general terms (Table 1), lineage IV was the most virulent overall, followed by lineage I $(P=0.04)$, and finally lineages II and III $(P=0.001)$. Lineages II and III were not significantly different from each other $(P=0.51)$, but were both significantly different from lineage I $(P=0.02)$. Within a lineage, some strains caused lower disease incidence on all of the maize accessions than did the other strains within the lineage, in particular strain 10793 in lineage I, strain 10812 in lineage II, strains 10799 and 10805 in lineage III, and strain 10803 in lineage IV. Removal of these strains from the statistical analysis increased the mean level of infection observed (Table 1 ), and removed $79 \%$ of the variation observed within a lineage, but did not otherwise significantly alter the responses (analysis not shown). We removed these less virulent strains prior to conducting nested analyses of variance to characterize the relative contributions of fungal lineage and isolate within a lineage (see below).

Lineage IV was the most virulent against six of seven accessions (Giza 4, Giza 102, Giza 221D, Giza 249C, Giza $251 \mathrm{~B}$, and K-64), and was never the least virulent. Lineage I was the most virulent

Table 3. A General Linear Model analysis of arcsine transformed mean percent infection of 15 isolates $^{\mathrm{y}}$ drawn from four lineages of Cephalosporium maydis tested against seven maize accessions ${ }^{\mathrm{z}}$ from single isolate inoculation tests for virulence

\begin{tabular}{lcccrc}
\hline Source & df & Type III SS & Mean square & $\boldsymbol{F}$ value & $\boldsymbol{P}>\boldsymbol{F}$ \\
\hline Experimental repetition & 1 & 0.1153 & 0.1153 & 6.14 & 0.0154 \\
Maize accession & 6 & 15.4235 & 2.5706 & 136.84 & 0.0001 \\
C. maydis lineage & 3 & 1.5852 & 0.5284 & 28.13 & 0.0001 \\
Repetition $\times$ accession & 6 & 0.4062 & 0.0677 & 3.60 & 0.0034 \\
Repetition $\times$ lineage & 3 & 0.0522 & 0.0174 & 0.93 & 0.4324 \\
Accession $\times$ lineage & 18 & 1.5256 & 0.0848 & 4.51 & 0.0001 \\
Repetition $\times$ accession $\times$ lineage & 18 & 0.2163 & 0.0120 & 0.64 & 0.8566 \\
Isolate (lineage) & 11 & 1.7291 & 0.1572 & 8.37 & 0.0001 \\
Accession $\times$ isolate (lineage) & 65 & 5.2009 & 0.0800 & 4.26 & 0.0001 \\
\hline
\end{tabular}

y See Table 2 for included C. maydis isolates.

z See Table 1 for included maize accessions. 
against accession Giza 307A. Lineage II was never the most virulent and was the least virulent against two accessions, Giza 102 and Giza 221D. Lineage III was never the most virulent and was the least virulent toward all of the accessions except for Giza 102 and Giza 221D (Table 1).

The GLM analysis of variance (Table 3) indicates that there are significant differences in mean percent infectivity between experimental repetitions $(P<0.02)$, among maize accessions $(P<0.0001)$, among $C$. maydis lineages $(P<0.0001)$, and among isolates nested within their respective lineages $(P<0.0001)$. Two-way interaction components between experimental repetition and maize accession, between maize accession and $C$. maydis lineage, and between maize accessions and isolates nested within their lineages, are all significant with $P$ values of $<0.004,<0.0001$, and $<0.0001$, respectively. The two-way interaction component between experimental repetition and $C$. maydis lineage is not significant $(P=0.43)$. This lack of significance indicates that despite the experimental noise in our greenhouse pot assay, the relative mean infectivity of the tested lineages is similar between experimental repetitions. Not surprisingly, the three-way interaction among experimental repetition, $C$. maydis lineage, and maize accession also was not significant $(P=0.86)$. Removal of the susceptible accessions from the statistical analysis removed $71 \%$ of the within-lineage variation. Removing both the weak strains and the susceptible accessions removed $80 \%$ of the within-lineage variation (analysis not shown).

Competitive colonization. Eighty-one isolates from 36 plants collected over the course of five sampling weeks from the first experiment (Table 4), and 113 isolates from 61 plants collected over the course of seven sampling weeks in a second experiment (Table 4) were characterized. In terms of overall percentages, lineage I isolates were recovered 15 and $8 \%$ of the time, lineage II isolates were recovered 74 and $65 \%$ of the time, and lineage III isolates were recovered 12 and $27 \%$ of the time, respectively, from the two experimental repetitions (Table 4). Lineage IV was not recovered at any time in either repetition.

Only a single $C$. maydis lineage was recovered from 94 and $85 \%$ of the maize plants sampled in the two repetitions, respectively. In all but one of the cases where more than a single lineage was recovered from the same plant, a lineage II isolate was one of the two recovered components. While mixed infections do occur in these experiments, a lineage II isolate appears to be a component in the majority of cases.

Frequencies of recovery of lineage I and lineage II isolates were similar and could not be differentiated statistically between the two repetitions of the experiment. At least one lineage II isolate was recovered from 29 of $36(81 \%)$ plants in the first repetition and from 43 of $61(71 \%)$ plants in the second repetition (Table 4). At least one lineage I isolate was recovered from 5 of $36(14 \%)$ plants in the first repetition and from 7 of $61(12 \%)$ plants in the second repetition. The frequency of recovery of lineage III isolates increased significantly $\left(\chi^{2}\right.$ test, $\left.P<0.05\right)$ in the second repetition. At least one lineage III isolate was recovered from 4 of $36(11 \%)$ plants in the first repetition and from 19 of 61 (30\%) plants in the second repetition. The three lineages were not recovered with equal frequency in either of the two experimental repetitions ( $\chi^{2}$ test, $P<0.001$ for both).

\section{DISCUSSION}

We found differences in the ability of the different lineages to cause disease symptoms in a maize plant in experiments in which single and multiple infections were possible. In the single infections, isolates from lineage IV were the most virulent, followed by lineages I, II, and III in approximately that order (Table 1). In terms of competitive ability in a multiple infection, however, lineage II was the most competitive, followed by lineages I and III (Table 4). Strains of lineage IV were not good competitors even though the strains used, 10792 and 10816, were quite capable of infecting and causing the late-wilt disease when used as the sole inoculum for the pot cultures (Table 1). The apparent negative correlation between the single inoculation and the multiple inoculation studies will require further work to resolve. Some possible explanations for these results include differences in the ability to grow either in the soil, in the host plant, or in the sorghum inoculum, differential sensitivity to other soil microbes or their metabolic products, and the ability to produce cellulases and other degradative enzymes that may be required to penetrate the plant's roots and permit colonization.

Due to physical constraints of greenhouse space, the number of isolates examined was limited, which may lead us to underestimate the pathogenic variability within each lineage. However, the isolates used in this study were selected to be rep-

Table 4. Amplified fragment length polymorphism (AFLP) lineages of strains of Cephalosporium maydis recovered from the cultivar Boushey in two repetitions of mixed-inoculum ${ }^{\mathrm{x}}$ competition experiments

\begin{tabular}{|c|c|c|c|c|c|c|}
\hline \multirow{2}{*}{$\begin{array}{c}\text { Time }^{y} \\
\text { (week) }\end{array}$} & \multicolumn{3}{|c|}{ 1st repetition } & \multicolumn{3}{|c|}{ 2nd repetition } \\
\hline & Lineage & Number of plants ${ }^{\mathrm{z}}$ & Mixed infections & Lineage & Number of plants ${ }^{\mathrm{z}}$ & Mixed infections \\
\hline \multirow[t]{3}{*}{1} & I & 3 & & I & 1 & \\
\hline & II & 4 & 1 & II & 5 & 1 \\
\hline & III & 0 & & III & 3 & \\
\hline \multirow[t]{3}{*}{2} & I & 0 & & I & 0 & \\
\hline & II & 8 & 0 & II & 4 & 1 \\
\hline & III & 0 & & III & 7 & \\
\hline \multirow[t]{3}{*}{3} & I & 0 & & I & 1 & \\
\hline & II & 5 & 0 & II & 1 & 0 \\
\hline & III & 0 & & III & 1 & \\
\hline \multirow[t]{3}{*}{4} & I & 0 & & I & 0 & \\
\hline & II & 5 & 1 & II & 6 & 0 \\
\hline & III & 3 & & III & 3 & \\
\hline \multirow[t]{3}{*}{5} & I & 2 & & I & 0 & \\
\hline & II & 7 & 0 & II & 11 & 1 \\
\hline & III & 1 & & III & 2 & \\
\hline \multirow[t]{3}{*}{6} & I & & & I & 4 & \\
\hline & II & No sample & & II & 13 & 5 \\
\hline & III & & & III & 3 & \\
\hline \multirow[t]{3}{*}{7} & I & & & I & 1 & \\
\hline & II & No sample & & II & 3 & 1 \\
\hline & III & & & III & 0 & \\
\hline
\end{tabular}

\footnotetext{
${ }^{x}$ See footnote to Table 2 for isolates used in mixed-inoculum experiments.

${ }^{y}$ First disease symptoms appeared approximately 60 days after planting. Week one is the date of the first sampling.

${ }^{\mathrm{z}}$ Number of plants from which at least one isolate from the indicated lineage was recovered. Only plants with visible disease symptoms were examined for the presence of the fungus.
} 
resentative in terms of lineages and geographic origins within Egypt (26). We observed some outliers in terms of virulence in the single strain inoculation studies (Table 1). In general, when we found outliers, those strains were less virulent than most of the other representatives of their lineage. These differences might be attributable to changes in virulence/competitiveness following laboratory maintenance. The stability of the results across replicate experiments, however, argues against this explanation. Alternatively, it is possible that mutations can occur that reduce the virulence, competitiveness, or general growth characters of a strain regardless of the background. If there is sufficient susceptible host material available within the Egyptian field populations then the selection against these weaker pathogens may not be sufficient to result in their rapid removal from the soil population. It also is possible that the less-virulent strains are favored due to as yet unidentified growth characters or environmental factors. The identification of such generally weakened strains in three of the four clonal lineages is consistent with this hypothesis. At this time we have not identified any common features that these weakened strains share that they do not share with other members of their lineage. Relative loss of virulence does not appear to be a property for which we have yet identified a suitable AFLP marker, and could be due to multiple causes.

When we conducted a nested analysis of virulence of $C$. maydis lineages on the array of maize inbreds (Table 3), we were not surprised to find that there were significant differences in mean infectivity among maize accessions and among lineages. However, we also observed differences in mean infectivity between experimental repetitions. Comparing the raw data for these two repetitions, we hypothesized that this difference between experimental repetitions was due to an overall higher mean infectivity in the first experimental repetition, and noted that this effect was especially pronounced on maize accession G-249C (data not shown). When the mean infectivity data for G-249C are removed from the data set, differences between experimental repetitions $(P=0.77$, data not shown), and in the two-way interaction between experimental repetition and accession $(P=0.44$, data not shown) become nonsignificant.

One possible recommendation resulting from this finding, and from the fact that accession G-249C is relatively susceptible to all four lineages (Table 1), is that this inbred be omitted from future greenhouse tests for virulence. However, the observed variation between experimental repetitions for G-249C also could indicate that some subtle microclimatic or physiological interaction occurs between $C$. maydis and this maize accession. Our analysis suggests that variation in the mean percent infection may be relatively sensitive and could be influenced by numerous variables. Analyzing and characterizing these more subtle pathogenic interactions will require specific testing that is beyond the scope of this study.

Earlier work with this fungus has included speculation that heterokaryons occurred and that plants were multiply infected with different strains of the pathogen (14). Our data are not of a type that would permit us to evaluate heterokaryosis. We did, however, identify multiply infected plants in our experiments (Table 4) and certainly anticipate that multiple infections for $C$. maydis can occur under field conditions, as has been documented for other stalk-rotting fungi, e.g., Fusarium verticillioides (=Fusarium moniliforme) (9). As we scored only the presence or absence of disease, we could not determine if there was a phenotypic difference between single and multiple infections.

Much of the present work in breeding for resistance to late wilt $(7,11,15,23,24)$, and in developing biological, cultural, and chemical controls $(1-3,8,13,22)$ has used potted plants in the greenhouse or nursery soils that were infested with multiple fungal isolates grown on sorghum grain in a manner similar to what we have done in our study. From our results, it is clear that these procedures need to be changed. For example, separate tests need to be run at least with strains from lineage IV if the previously obtained results are to be generalized to include this lineage. Separate tests of isolates from lineage II also are advisable, since this lineage seems to numerically overwhelm the others in infected plants. It also would be interesting to determine how representative strains from different lineages compete in simpler combinations, e.g., pairwise, rather than only as part of a single large group, which could be representative of some field populations.

As lineage IV was a poor competitor in our competition studies (Table 4), we expect that this lineage also could be relatively rare in fields in which susceptible maize varieties or hybrids are cultivated. As all of the lineages seem approximately equally virulent against the susceptible accessions we examined, the differences in competitive ability should select against lineage IV under these conditions. In such cases, we expect lineage IIs superior competitiveness to help it increase relative to the other $C$. maydis lineages that might be present. In fields sown to late-wilt "resistant" varieties or hybrids (which are attacked by lineage IV if they are attacked at all), however, we expect lineage IVs apparent virulence superiority to allow it to dominate, and to be more likely to cause enough damage to be noticeable in a commercial field. A detailed examination of populations of the fungus collected from fields of appropriate commercial hybrids and varieties grown in the Nile River delta is needed to test this hypothesis, and is currently in progress (17).

In conclusion, we found that the four clonal lineages we previously identified in Egypt by using AFLP markers also differ in their virulence and competitiveness towards maize plants grown under greenhouse conditions. These differences include not only differences in virulence in maize accession $\times$ fungal lineage interactions, but also in the competitiveness of strains of different lineages in a mixed inoculum. These differences suggest that standard protocols used to screen for resistance to this pathogen, which utilize mixed inocula, need to be altered and that field populations of this fungus may vary and may be affected by the resistance of the host variety or hybrid planted in the field.

\section{ACKNOWLEDGMENTS}

We thank researchers in the Maize section of the Field Crops Research Institute for providing the maize seed used in this study, A. Beyer and A. Clouse for technical assistance, and T. Todd and R. L. Bowden for assistance with the statistical analysis. This research was supported in part by the Agricultural Technology Utilization and Transfer project no. 58-3148-7-057 from the U.S. Agency for International Development (Cairo), and by the Kansas Agricultural Experiment Station. Manuscript no. 01-252-J from the Kansas Agricultural Experiment Station, Manhattan.

\section{LITERATURE CITED}

1. Abdel-Rahim, M. F., Shata, H. M., El-Fahl, A M., El-Assiuty, E. M., and Gouda, A. A. 1984. Cultural practices in relation to control of maize stalk-rot complex. Egypt. Agric. Res. Rev. 62:63-74.

2. Dawood, N. A., and Sabet, K. A. 1979. Effect of organic amendment and fungicidal application on the population of soil microflora and infection with the late-wilt disease of maize. Ann. Agric. Sci., Moshtohor 11:217-226.

3. El-Assiuty, E. M., El-Hamahmy, A.-A., and El-Sharkawy, A. Y. 1991. Bacillus subtilis, Pseudomonas fluorescens and Verticillium tricorpus as biological agents against late-wilt of maize. Egypt. J. Appl. Sci. 6:824-829.

4. El-Assiuty, E. M., Ismael, A. M., Zeller, K. A., and Leslie, J. F. 1999. Relative colonization ability of greenhouse-grown maize by four lineages of Cephalosporium maydis from Egypt. Phytopathology 89:S23.

5. El-Shafey, H. A., Abdel-Rahim, M. F., Abd-elAzim, O. Z., and Abd-el-Hamid, M. S. 1976. Carry-over of maize stalk-rot fungi in seed. Egypt. Agric. Res. Rev. 54:29-42.

6. El-Shafey, H. A., and Claflin, L. E. 1999. Late wilt. Pages 43-44 in: Compendium of Corn Diseases, 3rd ed. D. G. White, ed. The American Phytopathological Society, St. Paul, MN.

7. El-Shafey, H. A., El-Shorbagy, F. A., Khalil, I. I., and El-Assiuty, E. M. 1988. Additional sources of resistance to the late-wilt disease of maize caused by Cephalosporium maydis. Egypt. Agric. Res. Rev. 66:221-230.

8. El-Shafey, H. A., Mahmoud, S. A. Z., ElBrolousy, M., El-Azhary, T. M., and Ibrahim, T. F. 1990. Biological control of late-wilt disease by inoculation with Bacillus subtilis and manuring. Egypt. J. Appl. Sci. 5:182-191.

9. Kedera, C. J., Leslie, J. F., and Claflin, L. E. 1994. Genetic diversity of Fusarium section Liseola (Gibberella fujikuroi) in individual 
maize plants. Phytopathology 84:603-607.

10. Kerényi, Z., Zeller, K. A., Hornok, L., and Leslie, J. F. 1999. Regularization of matingtype terminology in the Gibberella fujikuroi species complex. Appl. Environ. Microbiol. 65:4071-4076.

11. Labib, H. A., Abdel-Rahim, M. E., Salem, A., and Abdel-Fattah, A. 1975. D.C. 19, A new maize hybrid seed resistant to late-wilt disease caused by Cephalosporium maydis. Egypt. Agric. Res. Rev. 53:1-4.

12. Murray, M. G., and Thompson, W. F. 1980. Rapid isolation of high molecular weight plant DNA. Nucleic Acids Res. 8:4321-4325.

13. Sabet, K. A., Samra, A. S., and Abdel-Rahim, M. F. 1972. Systemic action of benomyl against late-wilt disease of maize. Ann. Appl. Biol. 71:211-218.

14. Sabet, K. A., Samra, A. S., and Khalil, I. H. I. 1966. Variation in Cephalosporium maydis, the cause of the late-wilt disease. Pages 46-93 in: Investigations on Stalk-Rot Diseases of Maize in U.A.R. A. S. Samra, and K. A. Sabet, eds. Ministry of Agriculture, Government Printing Offices, Cairo, Egypt.

15. Sabet, K. A., Samra, A. S., and Mansour, I. M. 1968. A technique for testing maize varieties against the late-wilt disease caused by Cephalosporium maydis. Egypt. Agric. Res. Rev. 46:23-29.

16. Sabet, K. A., Zaher, A. M., Samra, A. S., and Mansour, I. M. 1970. Pathogenic behavior of Cephalosporium maydis and C. acremonium. Ann. Appl. Biol. 66:257-263.

17. Saleh, A. A., Zeller, K. A., El-Assiuty, E. M., and Leslie, J. F. 2000. AFLP diversity of Cephalosporium maydis in Egypt. Phytopathology 60:S68.

18. Samra, A. S., and Sabet, K. A. 1966. An introductory note. Pages 1-7 in: Investigations on Stalk-Rot Diseases of Maize in U.A.R. A. S. Samra and K. A. Sabet, eds. Ministry of Agriculture, Government Printing Offices, Cairo, Egypt.

19. Samra, A. S., Sabet, K. A., and Abdel-Rahim, M. F. 1966. Seed transmission of stalk-rot fungi and effect of seed treatment. Pages 94116 in: Investigations on Stalk-Rot Diseases of Maize in U.A.R. A. S. Samra and K. A. Sabet, eds. Ministry of Agriculture, Government Printing Offices, Cairo, Egypt.

20. Samra, A. S., Sabet, K. A., and Hingorani, M. K. 1962. A new wilt disease of maize in Egypt. Plant Dis. Rep. 46:481-483.
21. Samra, A. S., Sabet, K. A. and Hingorani, M. K. 1963. Late wilt disease of maize caused by Cephalosporium maydis. Phytopathology 53:402-406.

22. Shata, H. M., El-Assiuty, E. M., Abdel-Al, H R., and Gouda, A. A. 1984. Chemical contro of maize stalk-rot complex. Egypt. Agric. Res. Rev. 62:55-61.

23. Shehata, A. H. 1976. Gene action involved in the manifestation of late wilt (Cephalosporium maydis) of maize. Egypt. J. Genet. Cytol. 5:42-47.

24. Shehata, A. H., and Salem, A. M. 1972. Genetic analysis of resistance to late-wilt of maize caused by Cephalosporium maydis. Sabrao J. 4:1-5.

25. Vos, P., Hogers, R., Bleeker, M., Reijans, M. van de Lee, T., Hornes, M., Frijters, A., Pot, J., Peleman, J., Kuiper, M., and Zabeau, M 1995. AFLP: A new technique for DNA fingerprinting. Nucleic Acids Res. 23:44074414.

26. Zeller, K. A., Jurgenson, J. E., El-Assiuty, E. M., and Leslie, J. F. 2000. Isozyme and amplified fragment length polymorphisms (AFLPs) from Cephalosporium maydis in Egypt. Phytoparasitica 28:121-130. 